\title{
Reinnervation of the diaphragm by the inferior laryngeal nerve to the phrenic nerve in ventilator-dependent tetraplegic patients with C3-5 damage
}

\author{
Eric Verin ${ }^{1,2,3}$, Capucine Morelot-Panzini4,5, Jesus Gonzalez-Bermejo ${ }^{4,5}$, \\ Benoit Veber ${ }^{6}$, Brigitte Perrouin Verbe ${ }^{7}$, Brigitte Soudrie $^{8}$, Anne Marie Leroi ${ }^{2}$, \\ Jean Paul Marie ${ }^{1,9}$ and Thomas Similowski ${ }^{4,5}$
}

\begin{abstract}
Affiliations: ${ }^{1} E A$ 3830, Normandy University, Groupe de recherche sur le handicap ventilatoire (GRHV), Université de Rouen, Rouen, France. ${ }^{2}$ Service de physiologie, CHU de Rouen, Rouen, France. ${ }^{3}$ CRMPR les herbiers, Bois Guillaume, France. ${ }^{4}$ AP-HP, Groupe Hospitalier Pitié-Salpêtrière Charles Foix, Service de Pneumologie et Réanimation Médicale (Département "R3S"), Paris, France. ${ }^{5}$ Sorbonne Universités, UPMC Univ Paris 06, INSERM, UMRS1158 Neurophysiologie respiratoire expérimentale et clinique, Paris, France. ${ }^{6}$ Service de réanimation chirurgicale, $\mathrm{CHU}$ de Rouen, Rouen, France. ${ }^{7}$ Service de MPR, CHU de Nantes, Nantes, France. ${ }^{8}$ SSR Handicap Lourd, Hopital marin, Hendaye, France. ${ }^{9}$ Service d'ORL et Chirurgie Cervicofaciale CHU de Rouen, Rouen, France.
\end{abstract}

Correspondence: Eric Verin, Rouen University Hospital, 1 rue de Germont, 76031 Rouen Cedex, France. E-mail: eric.verinachu-rouen.fr

ABSTRACT The aim of this study was to evaluate the feasibility of unilateral diaphragmatic reinnervation in humans by the inferior laryngeal nerve. This pilot study included chronically ventilated tetraplegic patients with destruction of phrenic nerve motoneurons.

Five patients were included. They all had a high level of tetraplegia, with phrenic nerve motor neuron destruction. They were highly dependent on ventilation, without any possibility of weaning. They did not have other chronic pathologies, especially laryngeal disease. They all had diaphragmatic explorations to diagnose the destruction of the motoneurons of the phrenic nerves and nasoendoscopy to be sure that they did not have laryngeal or pharyngeal disease. Then, surgical anastomosis of the right phrenic nerve was performed with the inferior laryngeal nerve, by a cervical approach. A laryngeal reinnervation was performed at the same time, using the ansa hypoglossi.

One patient was excluded because of a functional phrenic nerve and one patient died 6 months after the surgery of a cardiac arrest. The remaining three patients were evaluated after the anastomosis every 6 months. They did not present any swallowing or vocal alterations. In these three patients, the diaphragmatic explorations showed that there was a recovery of the diaphragmatic electromyogram of the right and left hemidiaphragms after 1 year. Two patients had surgical diaphragmatic explorations for diaphragmatic pacing 18-24 months after the reinnervation with excellent results. At 36 months, none of the patients could restore their automatic ventilation.

In conclusion, this study demonstrated that diaphragmatic reinnervation by the inferior laryngeal nerve is effective, without any vocal or swallowing complications.

@ERSpublications

Feasibility, safety and usefulness of phrenic neurotisation by the inferior laryngeal nerve in tetraplegic patients http://ow.ly/6S5s30fD2lf

Cite this article as: Verin E, Morelot-Panzini C, Gonzalez-Bermejo J, et al. Reinnervation of the diaphragm by the inferior laryngeal nerve to the phrenic nerve in ventilator-dependent tetraplegic patients with C3-5 damage. ERJ Open Res 2017; 3: 00052-2017 [https://doi.org/10.1183/ 23120541.00052-2017].

Copyright $\odot$ ERS 2017. This article is open access and distributed under the terms of the Creative Commons Attribution Non-Commercial Licence 4.0. 


\section{Introduction}

The incidence of traumatic spinal injury worldwide ranges between 8 and 250 cases per million inhabitants per year depending on the country $[1,2]$, with the most common anatomical region of injury being the cervical spine ( $50 \%$ of cases) [1]. $2-5 \%$ of spinal injury patients suffer from long-term ventilator dependency [3,4], a condition associated with shorter life-expectancy [5] related to an increased risk of pneumonia and other respiratory complications [4]. In addition, tracheotomy and ventilator-dependency interfere with speech and olfaction [6], contributing to the impaired quality of life and social isolation.

Diaphragm pacing is a validated therapeutic approach that allows certain spinal injury patients to be weaned from mechanical ventilation [7, 8]. It improves gas exchange [9], reduces the frequency of respiratory infections [10], and improves speech, olfaction and quality of life $[6,10,11]$. It also reduces health costs [10] and tends to prolong life-expectancy [10]. However, diaphragm pacing is only possible if there is a conduit for phrenic nerve stimulation: loss of the phrenic motor neuron pool (C3-C4-C5 damage) renders patients ineligible for diaphragm pacing. They remain ventilator-dependent on a permanent basis.

To circumvent this outcome, restoration of diaphragm innervation through nerve transfers into the phrenic nerve has been proposed [12]. Animal studies have consistently documented that this is feasible [13-21]. Clinical results have been obtained in tetraplegic patients, using intercostal nerves [22-24] or the spinal accessory nerve $[22,25]$. The vagus nerve has also been considered for this purpose [26].

The ultimate goal of diaphragmatic reinnervation in tetraplegia would be to allow efficient spontaneous ventilation to resume. This cannot be achieved with infralesional donor nerves: intercostal transfers imply the subsequent use of phrenic stimulators to recondition the diaphragm and produce ventilation [22-24]. The accessory spinal nerve is supralesional, but it does not receive central respiratory inputs. Reconditioning the diaphragm after a spinal transfer involves either phrenic stimulation [22] or specific trapezius-targeted training procedures [25]. While an accessory spinal nerve transfer makes volitional breathing possible [25], it is not expected to result in automatic breathing. KAUFMAN et al. [22] mentioned that two patients that had been treated with this technique could sustain breathing autonomously for several hours, but this could have been the result of volitional control and no evidence of automatic breathing, i.e. during sleep, was obtained.

The inferior laryngeal nerve, a branch of the vagus nerve [27], is supralesional to cervical spinal cord lesions. Innervating the posterior cricoarytenoid muscle that adducts the vocal folds, this nerve carries rhythmic inspiratory discharges that originate in brainstem respiratory central pattern generators during breathing [28]. It starts firing in a coordinated manner with the phrenic nerve and before it [29]. As both a supralesional and respiratory nerve, the inferior laryngeal nerve is an excellent candidate for diaphragmatic reinnervation. The recovery of spontaneous diaphragm activity after inferior laryngeal nerve transfer has been documented consistently, over time, in animal models of phrenic section and spinal section $[13,15,16,18]$. In humans, laryngeal reinnervation using the phrenic nerve has been successfully reported [30], but there are currently no data regarding the opposite, i.e. diaphragmatic reinnervation using the inferior laryngeal nerve. The present study was undertaken to test the feasibility of this approach in patients with high spinal lesions and phrenic motor neurons loss. The protocol included unilateral termino-terminal anastomosis of the right phrenic nerve with the right inferior laryngeal nerve, and subsequent implantation of intradiaphragmatic phrenic stimulators [31] to accelerate diaphragm reconditioning in the event of actual reinnervation.

\section{Methods}

\section{Ethics}

The study was conducted according to the principles of the declaration of Helsinki. It was approved by the appropriate legal and ethical French authority (CPP Nord Ouest 1, 2007-036), and publicly registered (ClinicalTrials.gov identifier: NCT01350297). The patients received a detailed description of the study. They formally agreed to participate in the presence of a person designated by them, according to the French law, and who signed the consent forms on their behalf.

Received: April 282017 | Accepted after revision: Aug 112017

Clinical trial: This study is registered at clinicaltrials.gov with identifier number NCT01350297.

Support statement: French national grant PHRC: 2007-A00842-51. C. Morelot-Panzini, J. Gonzalez-Bermejo and T. Similowski are supported by the programme "Investissement d'Avenir ANR-10-AIHU 06" of the French Government. Funding information for this article has been deposited with the Crossref Funder Registry

Conflict of interest: Disclosures can be found alongside this article at openres.ersjournals.com 


\section{Patients}

Five patients were included in the study (table 1). They all had American Spinal Injury Association Impairment Scale (ASIA) A tetraplegia due to cervical spinal cord lesions, with a C2-C3 lesional level and damages extending to $\mathrm{C} 4-\mathrm{C} 6$ on magnetic resonance imaging. They were tracheostomised and permanently dependent on ventilation. They did not have other chronic pathologies and had no evidence of laryngeal disorders.

\section{Preoperative investigations}

Diaphragm responses to phrenic and transcranial stimulations

Diaphragmatic surface electromyographic recordings were performed using skin taped silver cup electrodes (Biopac, Santa Barbara, CA, USA) filled with a conductive paste and positioned in the lowest accessible intercostal space close to the costochondral junction to optimise the quality of the signal [32]. The electromyographic signals were recorded using an electromyogram (EMG) 100C amplifier (Biopac) with a $20 \mathrm{kHz}$ digitisation frequency within a $2-5 \mathrm{kHz}$ bandwidth. Tracheal pressure was measured using a catheter (110 cm long; $1.4 \mathrm{~mm}$ internal diameter) placed in the tracheal tube, $3 \mathrm{~cm}$ from its distal orifice. The pressure was recorded using a DL amplifier (Biopac) with a $1 \mathrm{kHz}$ digitisation frequency. Abdominal wall displacements were assessed using a piezo-electric mechanical sensor (Biopac), with a $1 \mathrm{kHz}$ digitisation frequency.

Before performing stimulations, the patients were disconnected from the ventilator for $20 \mathrm{~s}$ or until transcutaneous pulsed oxygen saturation fell below 85\%, to study spontaneous ventilation ("presence" or "absence"). After reconnection and reoxygenation, cervical magnetic stimulation (CMS) [33] was performed using a Magstim 200 stimulator equipped with a circular doughnut-shaped $90 \mathrm{~mm}$ coil producing a maximum output of $2.5 \mathrm{~T}$ (Magstim, Whitland, Dyfed, UK). The coil itself was centred over the spinous process of the seventh cervical vertebra. Transcranial magnetic stimulation (TMS) [34] was performed with a circular coil positioned over the vertex (thus stimulating both hemispheres) and with the handle in the sagittal plane. Various anteroposterior locations were tested to determine the best response in terms of the motor evoked potential of the target muscle. The position of the coil was marked precisely on the scalp and was subsequently maintained carefully. Three reproducible responses were then recorded for cervical and transcranial magnetic stimulation. A few seconds before the magnetic stimulation, patients were disconnected from the ventilator, and stimulations were always carried out at end expiration, tracheal tube occluded.

For all the stimulations, conduction times were measured from the stimulation artefact to the first departure from baseline, if any; motor evoked potential amplitudes were measured from peak to peak; tracheal pressure amplitude was measured from baseline to peak; and abdominal displacements were described as "absent", "increase in abdominal circumference", or "decrease in abdominal circumference". To consider that there was actually no diaphragm response to stimulation and therefore a complete loss of phrenic motor neurons, the following criteria had to be met: 1) absence of any EMG signal following cervical or transcranial magnetic stimulation; and 2) absence of any mechanical response in terms of tracheal pressure and abdominal displacement. Because CMS coactivates the diaphragm and other inspiratory muscles, a negative pressure response associated with a decrease in abdominal circumference was accepted in the absence of EMG response (indeed, diaphragmatic contractions simultanously lower intrathoracic pressure and increase abdominal pressure, hence an increase in abdominal circumference; a decrease in abdominal circumference indicates that muscles other than the diaphragm are responsible for any negative intrathoracic pressure observed after cervical or transcranial magnetic stimulation).

\section{TABLE 1 Characteristics of the patients}

$\begin{array}{llcccccc}\text { Patient } & \text { Sex } & \begin{array}{c}\text { BMI } \\ \mathbf{k g} \cdot \mathbf{m}^{-\mathbf{2}}\end{array} & \begin{array}{c}\text { Metamere lesion } \\ \text { length on MRI }\end{array} & \begin{array}{c}\text { ASIA } \\ \text { score }\end{array} & \begin{array}{c}\text { Age at tetraplegia } \\ \text { years }\end{array} & \begin{array}{c}\text { Age at reinnervation } \\ \text { years }\end{array} & \begin{array}{c}\text { Cause of } \\ \text { tetraplegia }\end{array} \\ \text { \#1 } & \text { Male } & 28 & \text { C3-C6 } & \text { A } & 19 & 20 & \text { Traffic crash } \\ \text { \#2 } & \text { Female } & 31 & \text { C2-C5 } & \text { A } & 21 & 53 & \text { Sport accident } \\ \text { \#3 } & \text { Male } & 22 & \text { C2-C5 } & \text { A } & 53 & 41 & \text { Sport accident } \\ \text { \#4 } & \text { Male } & 29 & \text { C2-C6 } & \text { A } & 39 & 37 & \text { Farming accident } \\ \text { \#5 } & \text { Female } & 28 & \text { C3-C4 } & \text { A } & 35 & \text { Spinal artery occlusion }\end{array}$

BMI: body mass index; MRI: magnetic resonance imaging; ASIA: American Spinal Injury Association Impairment Scale. 


\section{Nasoendoscopy}

A nasoendoscopy was performed in all patients to assess the normality of the pharyngolarynx and the absence of vocal folds lesions (ENFGP 20, Olympus, Hamburg, Germany). The nasoendoscope was protected by a slide-on endosheath system (Medtronic Xomed Inc, Jacksonville, FL, USA) after decontamination. It was introduced into one nostril without topical anaesthesia and then the velum, the pharynx and the mobility and the sensitivity of the larynx were carefully assessed. Swallowing was assessed with puree consistency foods and liquids. For liquids, aspirations were also researched with the nasoendoscope placed into the trachea through the tracheostomy tube. Swallowing function was qualitatively analysed [35].

\section{Selection for surgery}

Diaphragm responses and nasoendoscopy were analysed independently by three of the authors (E.V., J.P.M. and T.S.). The patients were selected for reinnervation surgery if there was no spontaneous ventilatory activity, no diaphragm response to CMS in terms of EMG, tracheal pressure and abdominal displacement [34], no diaphragmatic response to TMS, no morphological pharyngolaryngeal anomaly, and normal swallowing function under mechanical ventilation.

\section{Surgery}

All patients were operated by the same surgeon (J.P.M.), at Rouen University Hospital, after medical transportation to this site (under the supervision of B.V.). A lateral cervicotomy was performed under aseptic conditions. The right phrenic nerve and the cervical roots were exposed and the phrenic nerve was identified by anatomical landmarks. Its axonal degeneration was verified by direct electrical nerve stimulation (2 mA) (VariStim RIII, Medtronic Xomed Inc). The phrenic nerve was then sectioned in the neck below the sixth cervical root. A retrograde dissection of the inferior laryngeal nerve was performed, in the caudal direction, avoiding opening the tracheotomy space to elude any contamination from the cervical wound. An anastomosis was then performed between the distal part of the right phrenic nerve and the proximal part of the right inferior laryngeal nerve trunk, sectioned just below the laryngeal entrance. End-to-end epi-perineural sutures were made with 9.0 nylon thread.

With the aim to mitigate the consequences of laryngeal denervation on phonation and the risk of aspiration, laryngeal reinnervation and vocal fold medialisation was performed at the same time. The ansa hypoglossi was dissected close to the jugular vein, and followed distally until the strap muscles where the nerve was cut. An end-to-end anastomosis was then performed between the ansa hypoglossi and the distal portion of the inferior laryngeal nerve (with the same microsurgical technique, under magnification) [36]. The cervical wound was closed with drainage. Additionally, to wait for the axonal regrowth (usually 4 months), homolateral right vocal cord medialisation was performed, by an endoscope approach (suspension laryngoscopy), using small pieces of fat harvested from a peri-umbilical incision, and placed in a high-pressure Broninge syringe. The vocal cord was filled with $1 \mathrm{~mL}$ of fat, injected into the membranous medial portion of the vocal muscle.

\section{Follow-up}

The preoperative investigations were repeated at day 10 post-surgery, and then after 1, 6, 12, 18 and 24 months.

\section{Diaphragm pacing}

The implantation of intradiaphragmatic phrenic nerve stimulators (NeurRxRA/4 Diaphragm Pacing System, Synapse Biomedical, Cincinnatti, OH, USA) [31] was proposed to those patients in which a diaphragm response to CMS appeared during follow-up, but without recovery of spontaneous respiratory activity, according to the hypothesis that this situation was due to persistent diaphragmatic atrophy in spite of reinnervation. All the patients were operated at the same site (Pitié-Salpêtrière hospital) by a surgeon with extensive experience with this approach, and according to the laparoscopic procedures described for this technique [31].

\section{Results}

\section{Preoperative investigations}

None of the patients exhibited spontaneous ventilation when disconnected from the ventilator, even when arterial oxygen saturation measured by pulse oximetry fell to $80 \%$.

All patients fulfilled the criteria for phrenic motor loss according to cervical and transcranial magnetic stimulation (complete absence of both EMG and mechanical responses to stimulation in four cases (figure 1); absence of EMG and negative tracheal pressure and decrease in abdominal circumference in one case (\#2); see methods). The nasoendoscopic evaluation was normal in all patients, and no abnormality in the swallowing function was detected. All patients could audibly speak under mechanical 

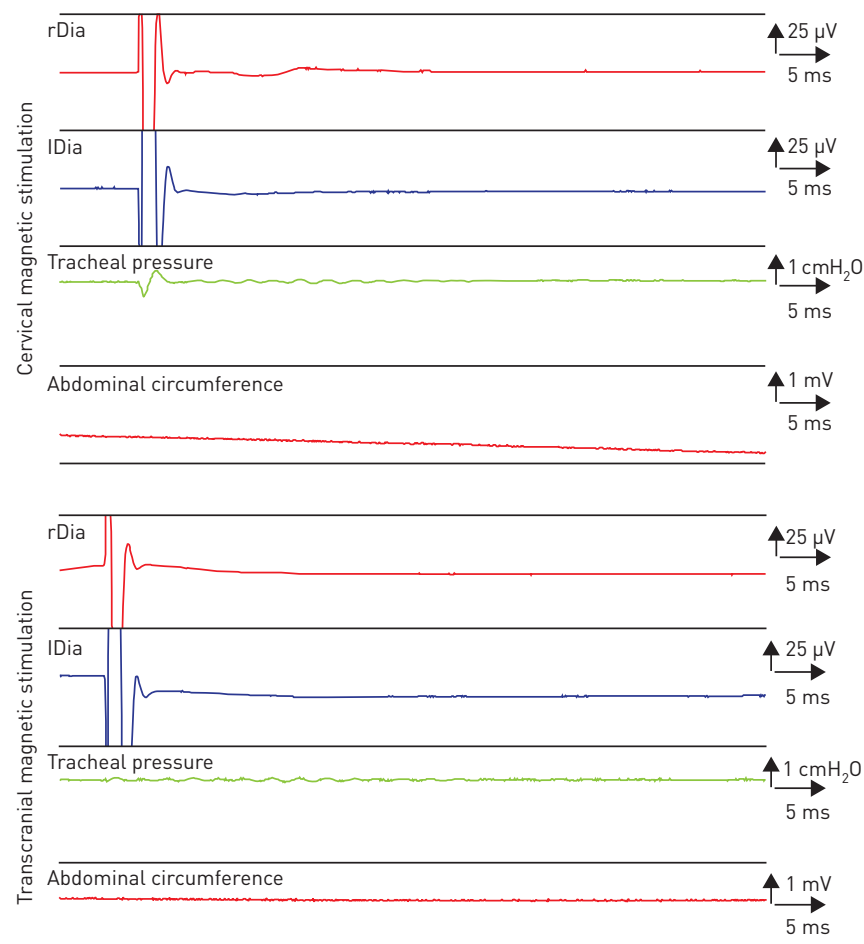

FIGURE 1 Raw data of typical diaphragmatic explorations in patient \#5, showing absence of diaphragmatic motor evoked potential and no change of tracheal pressure and abdominal deflation before surgery. rDia: right recording of the diaphragmatic electromyography; IDia: left recording of the diaphragmatic electromyography.

ventilation, but all exhibited the phonation difficulties typical to tracheotomised and mechanically ventilated tetraplegics $[37,38]$.

\section{Surgery and immediate post-operative care}

In one patient $(\# 2)$, direct electrical stimulation of the exposed right phrenic nerve resulted in unambiguous diaphragm responses with visible abdominal expansion. Therefore, the procedure was stopped and the patient excluded from the study (this patient was subsequently implanted with phrenic stimulators and weaned from mechanical ventilation). In the other four patients, no diaphragmatic contractions were observed in response to direct phrenic nerve stimulation, and the procedure was successfully carried out, as described in the methods section.

The post-operative length of stay in the intensive care unit ranged from 5 to 8 days. The first post-operative diaphragm assessments (day 10 and month 1) did not reveal any change. No early troubles with swallowing were detected. No significant changes in voice were reported by the patients, their next of kin and their caregivers. Endoscopic evaluation showed that the right vocal fold was always paralysed in the medial position, with a complete laryngeal closure.

\section{Follow-up from 6 to 24 months}

General follow-up

One patient (\#3) suddenly died at 6 months (unexplained cardiac arrest). One patient (\#4) suffered from a moderately severe pulmonary embolism 15 days after surgery, with no subsequent episode after anticoagulant treatment and no distant consequences. One patient (\#5) suffered from severe pneumonia with septicaemia (Candida albicans) and from an urinary tract infection (Pseudomonas aeruginosa) at 1 year, with complete resolution under appropriate antibiotic therapy.

\section{Specific follow-up}

Patients \#4 and \#5 underwent the complete follow-up programme $(6,12,18$ and 24 months), whereas patient \#1 refused the 18-month work-up. In these three patients, no change in nasoendoscopic findings was observed, there was no swallowing disorder for food or liquid and no episode of laryngeal aspiration or bronchial penetration, and there was no noticeable change in voice. The right vocal fold was always found in medial position at laryngeal examination. 
TABLE 2 Follow-up of the diaphragmatic assessments

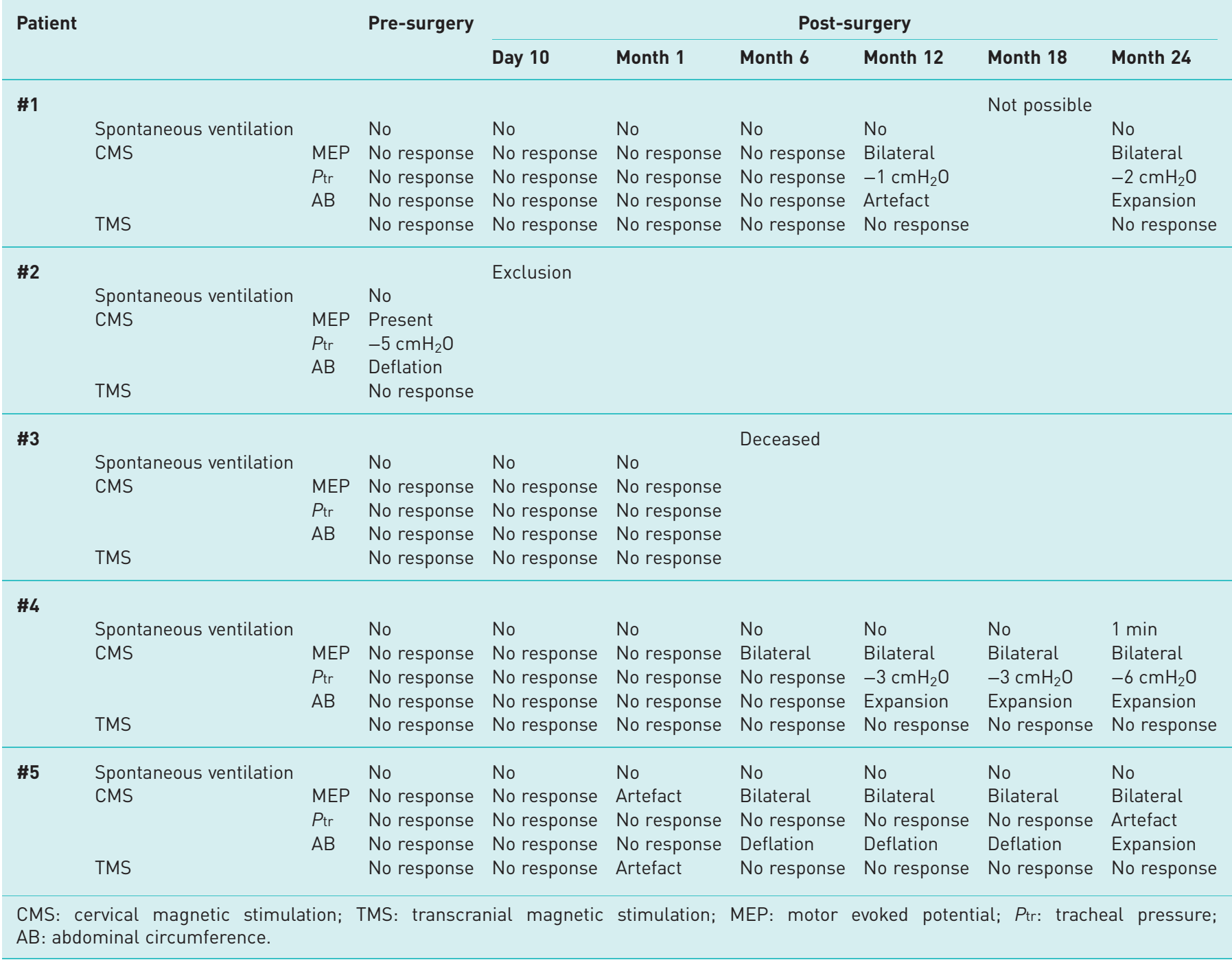

At 6 months, there was no response in patient \#1 and a bilateral response to CMS with right and left motor evoked potentials in patients \#4 and \#5 without any modification of tracheal pressure and abdominal circumference induced by bilateral phrenic nerve stimulation (tables 2 and 3). After 1 year, there was a bilateral electromyographic response to CMS in the three patients, with a negative tracheal pressure response in two cases (\#1 and \#4), and an increase in abdominal circumference (ascertaining positive abdominal pressure, hence diaphragm contraction) in one case (\#4) (table 2). After 2 years, the pattern of response to CMS was that of a diaphragm contraction in the three cases (increase in abdominal circumference) (table 2). The latencies and amplitudes of the diaphragm electromyographic responses to CMS are given in table 3. In view of these results, diaphragm pacing was proposed to the three patients. Patient \#4 refused, but patients \#1 and \#5 were actually implanted.

In patient $\# 1$, visible contractions of the diaphragm were observed in response to stimulations applied close to the anatomical landmark of the phrenic motor point during the laparoscopic implantation procedure, on both sides. However, diaphragm reconditioning proved impossible during the weeks and months following the implantation, even though 36 months after the inferior laryngeal nerve transfer and 12 months after the implantation of the phrenic stimulators intradiaphragmatic recordings (performed with the stimulating electrodes) evidenced a bilateral response to CMS (table 3). This response was of very small amplitude (table 3), with a quite decreased tracheal pressure and no change in abdominal circumference. After that the patient refused further investigations and in spite of several attempts no further intradiaphragmatic recordings could be performed. 


\begin{tabular}{|c|c|c|c|c|c|c|}
\hline Subject & & M6 & M12 & M18 & M24 & M36 \\
\hline \multirow[t]{4}{*}{ \#1 } & $\mathrm{r}$-PNCT ms & & 5.2 & Not possible & 5.5 & $6.05^{\#}$ \\
\hline & l-PNCT ms & & 5.2 & & 6.2 & 5.55 \\
\hline & r-MEP amplitude $\mu \mathrm{V}$ & & 102 & & 271 & 84 \\
\hline & L-MEP amplitude $\mu \mathrm{V}$ & & 60 & & 172 & 177 \\
\hline \multirow[t]{4}{*}{ \#4 } & $\mathrm{r}$-PNCT ms & 7.4 & 7.0 & 5.9 & 7.2 & \\
\hline & I-PNCT ms & 6.7 & 7.4 & 6.7 & 8.4 & \\
\hline & $r$-MEP amplitude $\mu \mathrm{V}$ & 45 & 151 & 102 & 174 & \\
\hline & L-MEP amplitude $\mu \mathrm{V}$ & 68 & 271 & 80 & 45 & \\
\hline \multirow[t]{4}{*}{ \#5 } & $\mathrm{r}$-PNCT ms & 7.0 & 6.2 & 6.7 & $6.8^{\#}$ & \\
\hline & l-PNCT ms & 5.8 & 7.4 & 5.4 & 5.9 & \\
\hline & $r$-MEP amplitude $\mu \mathrm{V}$ & 150 & 292 & 254 & 605 & \\
\hline & l-MEP amplitude $\mu \mathrm{V}$ & 280 & 328 & 245 & 439 & \\
\hline
\end{tabular}

In patient \#5, visible contractions of the diaphragm were also observed in response to stimulations applied closed to the anatomical landmark of the phrenic motor point during the laparoscopic implantation procedure, but on the right side only. Post-operatively, intradiaphragmatic recordings evidenced a contraction of the right hemidiaphragm during a phonatory exercise performed under mechanical ventilation (figure 2a) and during a voluntary sniff manoeuvre (figure $2 \mathrm{~b}$ ). CMS confirmed this pattern by showing a typical $\mathrm{M}$-wave response in the right hemidiaphragm (intramuscular recordings), but not in the left one (figure 3). Unfortunately, the patient died during the diaphragm reconditioning procedure.

\section{Discussion}

This study shows that nerve transfer from the right inferior laryngeal nerve to the right phrenic nerve is feasible in tetraplegic ventilator-dependent patients with cervical spinal cord lesions and loss of phrenic motor neurons. This echoes the reciprocal technique documented for laryngeal reinnervation [30] and extends to humans the data accumulated over time in animal models [13, 15, 16, 18]. This surgical approach, associated with right vocal fold medialisation and a concomitant transfer on the ansa hypoglossi to the severed laryngeal nerve, was not associated with post-operative swallowing problems and did not alter voice in a clinically detectable manner. It was associated with actual diaphragm reinnervation, even if at 36 months none of the patients could restore their automatic ventilation.

\section{Tolerance}

The physiology of voice production is dramatically modified in tetraplegic patients due to the lack of active expiration: subglottic pressure can only be built by the elastic recoil of the lungs [39]. This makes phonation difficult and fragile, with competition between gas exchange and speech production [38] and the need for a careful management of ventilatory support to preserve speech [37, 40, 41]. Since the ability to communicate verbally with others is a major determinant of quality of life in ventilator-dependent tetraplegic patients, it was very important to minimise the risk of deteriorating speech production. Based on previous research and experience [36, 42-45], we hypothesised that combining the laryngeal-phrenic anastomosis with an immediate medialisation of the vocal cord by thyroplasty and a reinnervation of the severed laryngeal nerve by anastomosis to a branch of the hypoglossal nerve (ansa hypoglossi) [45] should prevent this outcome. Detailed follow-up of our patients failed to identify any significant clinical abnormalities regarding speech production and swallowing/aspiration issues, both early and late after surgery. Therefore, we believe that the combination of surgical approaches we used is safe and acceptable in the clinical context of tetraplegia with ventilator-dependence, provided that any laryngeal dysfunction is ruled out before the operation. Of note, the inferior laryngeal nerve is a perfect theoretical candidate for phrenic reinnervation in the context of cervical spinal lesions because its origin is supralesional and because it is a respiratory nerve [28], but its role in laryngeal innervation rules out its use for bilateral phrenic reinnervation. However, one functional hemidiaphragm suffices to produce adequate alveolar 
ventilation at rest $[46,47]$ and during exercise in non-paralysed patients $[47,48]$, and should thus suffice to meet metabolic needs in tetraplegic patients.

\section{Recovery of diaphragm function}

There is no doubt that the four patients who actually underwent the laryngeal-phrenic anastomosis during our study had fully nonfunctional diaphragms at the time of inclusion. They had been tetraplegic and ventilator dependent for at least 12 months without clinical evolution and they had spinal lesions highly likely to be associated with phrenic motor neurons loss. CMS failed to elicit any electromyographic or mechanical response of the diaphragm. In addition, direct stimulation of the phrenic nerve during surgery failed to elicit any visible diaphragm contraction. With time, responses to CMS appeared in the three patients who could be followed for more than 6 months. In the three cases, these responses included an increase in abdominal circumference that is an unambiguous indication of diaphragm contraction (all the more so in the two cases where this was associated with a decrease in intrathoracic pressure). As a result, there is also no doubt that recovery of diaphragm function did occur. In addition to a typical mechanical response to CMS, electromyographic responses that were initially absent were noted 1 year after the operation. Unexpectedly, these responses were not confined to the right side (reinnervated) but were bilateral. This raises three hypotheses: 1) electromyographic signal contamination (the left electrode picking-up a signal originating on the right side); 2) concomitant graft-induced reinnervation on the right side and spontaneous recovery of the left side; and 3) actual bilateral reinnervation following unilateral nerve transfer. Of note, spontaneous recovery cannot be called upon to explain the reinnervation of the right hemidiaphragm in our patients, because their right phrenic nerve was cut through to perform the anastomosis with the inferior laryngeal nerve, at a level below the convergence of the C4 and C5 component of the phrenic nerve $[49,50]$. The observations made with intradiaphragmatic electrodes in patient \#5 (unilateral activation of the right hemidiaphragm not only during a sniff manoeuvre but also during phonatory exercises, and unilateral response of the right hemidiaphragm on CMS) do ascertain the fact the right hemidiaphragm actually got reinnervated by the inferior laryngeal nerve.

The bilateral nature of the electromyographic response to CMS could be purely artefactual, with the left electrode picking up a signal arising from the right hemidiaphragm (crosstalk or far field phenomenon). This hypothesis is made all the more likely by the recording montage that we used [32], which involves the right and left pairs of surface electrodes being much closer to one another than with usual diaphragm
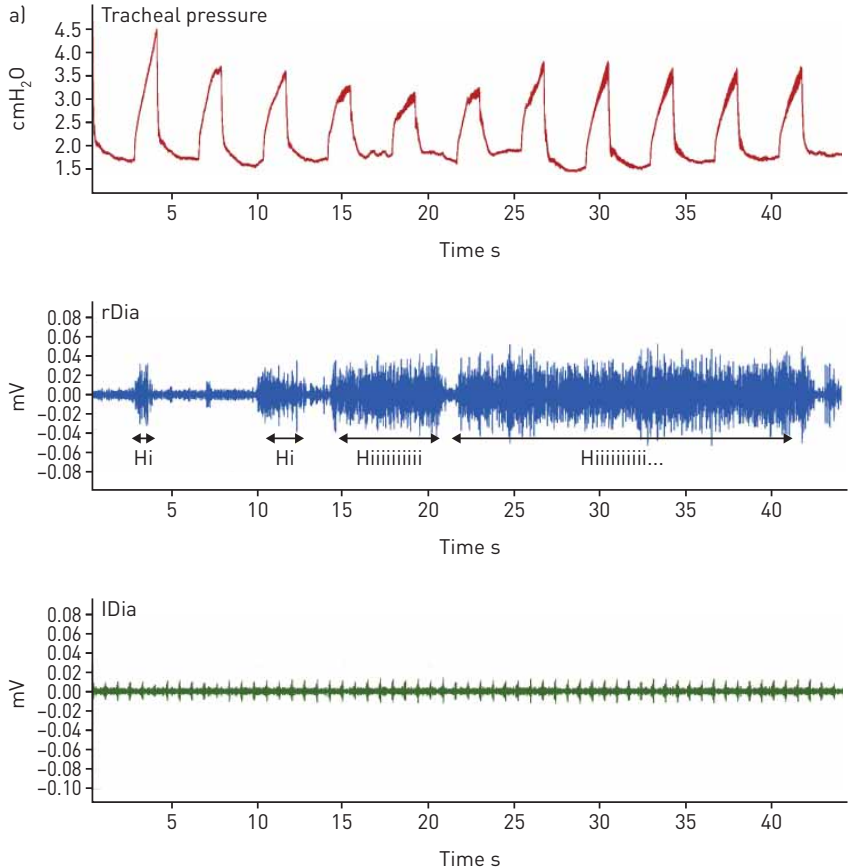
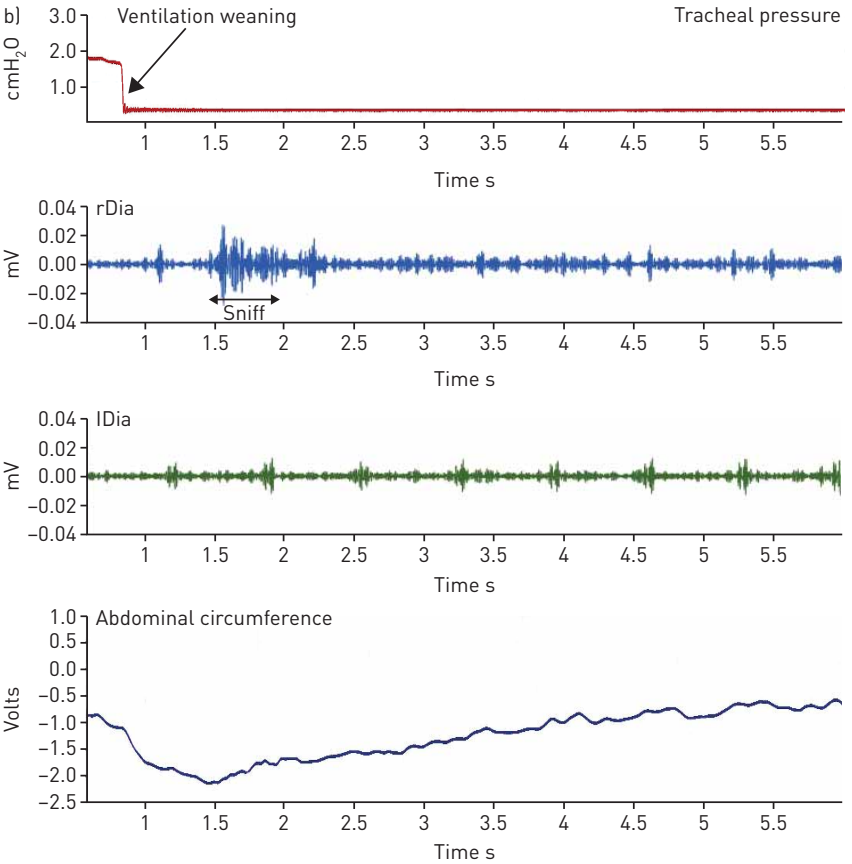

FIGURE 2 Right and left diaphragm recording in patient \#5. Recordings were obtained in patient \#5 just after phrenic pace maker implantation

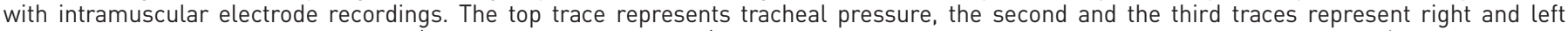
recordings of the diaphragmatic EMG (rDia and IDia, respectively) and the bottom trace represents abdominal displacements. a) The recordings were obtained under mechanical ventilation, the patient being asked to produce short (Hi) and long noises (Hiiiii). The diaphragmatic contraction documented by the increase in EMG intensity attests to the actual reinnervation with the inferior laryngeal nerve. b) Recordings obtained during a sniff manoeuvre with intramuscular electrode recordings. 


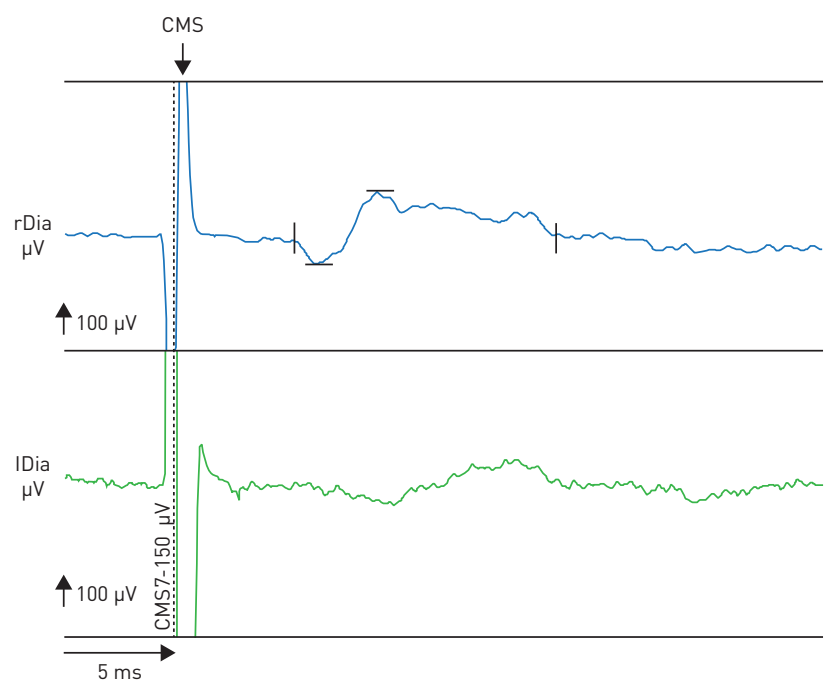

FIGURE 3 Electromyographic responses of the diaphagm to cervical magnetic stimulations (CMS), recorded with the intramuscular electrodes implanted for diaphragm pacing in patient \#5 (top trace right hemidiaphragm (rDia); bottom trace left hemidiaphragm (IDia)). There was a response of the right hemidiaphragm only.

montages [51, 52]. In patient \#5, we observed a bilateral response to CMS with surface electrodes, but the response was unilateral with intradiaphragmatic electrodes: this supports signal contamination. Yet, unilateral electromyographic diaphragm response to CMS has been reported [53], indicating that right-left signal contamination does not systematically occur with this technique. In addition, we observed a bilateral electromyographic response to CMS with intradiaphragmatic electrodes in patient \#1, a recording technique that makes crosstalk unlikely. Therefore, in this patient bilateral diaphragm recovery is impossible to rule out.

The spontaneous recovery of diaphragm function in patients with high cervical spinal cord lesions (at times involving C4) who had been ventilator-dependent for long periods of time and in whom phrenic stimulation had failed to elicit a diaphragm response has been described [54,55]. This could have occured on the left side in our patients, but the probability of observing this in all of them seems very low. This mechanism appears more probable in patient \#1, because of the bilateral nature of the intradiaphragmatic recordings at 36 months, than in patients \#4 and \#5 (where signal contamination remains the foremost hypothesis).

The third hypothesis to explain a bilateral response of the diaphragm to CMS in our patients (and particularly patient \#1) would be an actual reinnervation of the left hemidiaphragm triggered by the graft-induced right reinnervation. In normal individuals, diaphragm contractions are systematically bilateral. This is crucial to optimise the inspiratory action of the diaphragm, because unilateral diaphragm contractions not only develop less inspiratory force but also exert an expiratory force on the contralateral lung through the transmission of the positive abdominal pressure that they generate to this lung and through the noncontracting hemidiaphragm [56]. The neural mechanisms of the right-left coupling of the two hemidiaphragms are central in origin. The inspiratory neurons in the pre-Bötzinger complex project to the contralateral pre-Bötzinger complex both anatomically and functionally, commissural connections ensuring pre-Bötzinger bilateral synchrony [57-60]. In additon, phrenic premotor neurons located in the rostral part of the respiratory ventral group (rVRG) project bilaterally on spinal phrenic motor neurons [61]. The inferior laryngeal nerve originates in the nucleus ambiguus that belongs, with the pre-Bötzinger complex, to the rVRG. It could be postulated that diaphragmatic afferents carried by the right inferior laryngeal nerve after its anastomosis to the phrenic nerve and diaphragm reinnervation triggered the pre-Bötzinger complex to broadcast efferent messages to the left side, thereby inducing reinnervation of a pathway to the left diaphragm. Given the typology of the spinal lesions in our patients, this pathway could not have involved C4 spinal phrenic motor neurons. However, it could have involved C5 phrenic motor neurons, known to possibly contribute to an important contingent of the phrenic nerve [49] and that were infralesional in our patients. In patient \#1, diaphragm pacing could have contributed to amplify the process through retrograde stimulation. Specific animal models are needed to assess the plausibility of this very speculative mechanism.

\section{Limitations and open questions}

The very small size of the study population, the difficulties in obtaining homogeneous follow-up in our patients, and the very preliminary nature of the results are obvious limitations of our study. In addition to 
the bilateral reinnervation issue extensively discussed above, some of our observations are perplexing. For example, because we used a supralesional nerve to reinnervate the phrenic nerve, diaphragmatic reinnervation should have been associated with a recovery of the response to TMS. This was not the case even though in patient $\# 5$ the reinnervated diaphragm did respond to corticospinal inputs (voluntary sniff manoeuvre and phonatory exercises). Also, in spite of a patent diaphragm reinnervation, diaphragm pacing failed to achieve diaphragm reconditioning in patient \#1, for reasons unknown. The most important issue that our study leaves unresolved is the ability of the reinnervation of the phrenic nerve with the inferior laryngeal nerve to restore automatic ventilation, which remains theoretical at this stage. Nevertheless, our study demonstrates the feasibility, safety and effectiveness of phrenic neurotisation by the inferior laryngeal nerve in ventilator dependent tetraplegic patients with loss of phrenic motor neurons. This approach should now be evaluated in a larger cohort of patients, with the recovery of automatic ventilation as the main outcome.

\section{References}

1 Singh A, Tetreault L, Kalsi-Ryan S, et al. Global prevalence and incidence of traumatic spinal cord injury. Clin Epidemiol 2014; 6: 309-331.

2 Furlan JC, Sakakibara BM, Miller WC, et al. Global incidence and prevalence of traumatic spinal cord injury. Can J Neurol Sci 2013; 40: 456-464.

3 Devivo MJ. Epidemiology of traumatic spinal cord injury: trends and future implications. Spinal Cord 2012; 50: 365-372.

4 Shavelle RM, DeVivo MJ, Strauss DJ, et al. Long-term survival of persons ventilator dependent after spinal cord injury. J Spinal Cord Med 2006; 29: 511-519.

5 DeVivo MJ, Ivie CS III. Life expectancy of ventilator-dependent persons with spinal cord injuries. Chest 1995; 108: 226-232.

6 Adler D, Gonzalez-Bermejo J, Duguet A, et al. Diaphragm pacing restores olfaction in tetraplegia. Eur Respir J 2009; 34: 365-370.

7 Dalal K, DiMarco AF. Diaphragmatic pacing in spinal cord injury. Phys Med Rehabil Clin N Am 2014; 25 619-629.

8 Posluszny JA Jr, Onders R, Kerwin AJ, et al. Multicenter review of diaphragm pacing in spinal cord injury: successful not only in weaning from ventilators but also in bridging to independent respiration. $J$ Trauma Acute Care Surg 2014; 76: 303-309.

9 Gonzalez-Bermejo J, Morélot-Panzini C, Georges M, et al. Can diaphragm pacing improve gas exchange? Insights from quadriplegic patients. Eur Respir J 2014; 43: 303-306.

10 Hirschfeld S, Exner G, Luukkaala T, et al. Mechanical ventilation or phrenic nerve stimulation for treatment of spinal cord injury-induced respiratory insufficiency. Spinal Cord 2008; 46: 738-742.

11 Le Pimpec-Barthes F, Gonzalez-Bermejo J, Hubsch JP, et al. Intrathoracic phrenic pacing: a 10-year experience in France. J Thorac Cardiovasc Surg 2011; 142: 378-383.

12 Senjaya F, Midha R. Nerve transfer strategies for spinal cord injury. World Neurosurg 2013; 80: e319-e326.

13 Baldissera F, Cavallari P, Marini G, et al. Diaphragm reinnervation by laryngeal motoneurons. J Appl Physiol (1985) 1993; 75: 639-647.

14 Brown JO, Satinsky VP. Functional restoration of the paralyzed diaphragm following the cross-union of the vagus and phrenic nerves. Am J Med Sci 1951; 222: 613-622.

15 Derrey S, Verin E, Laquerriere A, et al. Restoration of diaphragmatic function after diaphragm reinnervation by inferior laryngeal nerve; experimental study in rabbits. Respir Res 2006; 7: 17.

16 Gauthier P, Baussart B, Stamegna JC, et al. Diaphragm recovery by laryngeal innervation after bilateral phrenicotomy or complete C2 spinal section in rats. Neurobiol Dis 2006; 24: 53-66.

17 Guth L, Frank K. Restoration of diaphragmatic function following vagophrenic anastomosis in the rat. Exp Neurol 1959; 1: 1-12.

18 Guth L, Soutter L, Frank K, et al. Diaphragmatic function following anastomosis of recurrent laryngeal and phrenic nerves. Exp Neurol 1960; 2: 251-260.

19 Sigmund L, Rigamonti D, Nylen E. Long-term functional restoration of the paralyzed hemidiaphragm in the dog. Exp Neurol 1981; 72: 531-543.

20 Wen J, Yang M, Li L, et al. Partial recovery of respiratory function and diaphragm reinnervation following unilateral vagus nerve to phrenic nerve anastomosis in rabbits. PLoS One 2013; 8: e79552.

21 Wilson AS, Krcek JP. Restoration of function in the paralyzed diaphragm. Exp Neurol 1975; 47: 490-502.

22 Kaufman MR, Elkwood AI, Aboharb F, et al. Diaphragmatic reinnervation in ventilator-dependent patients with cervical spinal cord injury and concomitant phrenic nerve lesions using simultaneous nerve transfers and implantable neurostimulators. J Reconstr Microsurg 2015; 31: 391-395.

23 Krieger AJ, Gropper MR, Adler RJ. Electrophrenic respiration after intercostal to phrenic nerve anastomosis in a patient with anterior spinal artery syndrome: technical case report. Neurosurgery 1994; 35: 760-763.

24 Krieger LM, Krieger AJ. The intercostal to phrenic nerve transfer: an effective means of reanimating the diaphragm in patients with high cervical spine injury. Plast Reconstr Surg 2000; 105: 1255-1261.

25 Yang ML, Li JJ, Zhang SC, et al. Functional restoration of the paralyzed diaphragm in high cervical quadriplegia via phrenic nerve neurotization utilizing the functional spinal accessory nerve. J Neurosurg Spine 2011; 15: 190-194.

26 Wang C, Liu J, Yuan W, et al. Anatomical feasibility of vagus nerve esophageal branch transfer to the phrenic nerve. Neural Regen Res 2012; 7: 703-707.

27 Schweizer V, Dorfl J. The anatomy of the inferior laryngeal nerve. Clin Otolaryngol Allied Sci 1997; 22: 362-369.

28 Fregosi RF, Ludlow CL. Activation of upper airway muscles during breathing and swallowing. $J$ Appl Physiol (1985) 2014; 116: 291-301.

29 Strohl KP, Hensley MJ, Hallett M, et al. Activation of upper airway muscles before onset of inspiration in normal humans. J Appl Physiol Respir Environ Exerc Physiol 1980; 49: 638-642. 
30 Li M, Chen S, Zheng H, et al. Reinnervation of bilateral posterior cricoarytenoid muscles using the left phrenic nerve in patients with bilateral vocal fold paralysis. PLoS One 2013; 8: e77233.

31 DiMarco AF, Onders RP, Ignagni A, et al. Phrenic nerve pacing via intramuscular diaphragm electrodes in tetraplegic subjects. Chest 2005; 127: 671-678.

32 Verin E, Straus C, Demoule A, et al. Validation of improved recording site to measure phrenic conduction from surface electrodes in humans. J Appl Physiol (1985) 2002; 92: 967-974.

33 Similowski T, Fleury B, Launois S, et al. Cervical magnetic stimulation: a new painless method for bilateral phrenic nerve stimulation in conscious humans. J Appl Physiol (1985) 1989; 67: 1311-1318.

34 Similowski T, Straus C, Coic L, et al. Facilitation-independent response of the diaphragm to cortical magnetic stimulation. Am J Respir Crit Care Med 1996; 154: 1771-1777.

35 Leder SB, Acton LM, Lisitano HL, et al. Fiberoptic endoscopic evaluation of swallowing (FEES) with and without blue-dyed food. Dysphagia 2005; 20: 157-162.

36 Crumley RL, Izdebski K. Voice quality following laryngeal reinnervation by ansa hypoglossi transfer. Laryngoscope 1986; 96: 611-616.

37 Prigent H, Samuel C, Louis B, et al. Comparative effects of two ventilatory modes on speech in tracheostomized patients with neuromuscular disease. Am J Respir Crit Care Med 2003; 167: 114-119.

38 Shea SA, Hoit JD, Banzett RB. Competition between gas exchange and speech production in ventilated subjects. Biol Psychol 1998; 49: 9-27.

39 Brown R, DiMarco AF, Hoit JD, et al. Respiratory dysfunction and management in spinal cord injury. Respir Care 2006; 51: 853-868.

40 Prigent H, Garguilo M, Pascal S, et al. Speech effects of a speaking valve versus external PEEP in tracheostomized ventilator-dependent neuromuscular patients. Intensive Care Med 2010; 36: 1681-1687.

41 Prigent $\mathrm{H}$, Lejaille $\mathrm{M}$, Terzi N, et al. Effect of a tracheostomy speaking valve on breathing-swallowing interaction. Intensive Care Med 2012; 38: 85-90.

42 Lagier A, Polle-Pelletier V, Giovanni A, et al. Vocal fold medialization: which are the available fillers in France in 2010? Eur Ann Otorhinolaryngol Head Neck Dis 2011; 128: 99-101.

43 Marie JP, Dehesdin D, Ducastelle T, et al. Selective reinnervation of the abductor and adductor muscles of the canine larynx after recurrent nerve paralysis. Ann Otol Rhinol Laryngol 1989; 98: 530-536.

44 Marina MB, Marie JP, Birchall MA. Laryngeal reinnervation for bilateral vocal fold paralysis. Curr Opin Otolaryngol Head Neck Surg 2011; 19: 434-438.

45 Crumley RL. Unilateral recurrent laryngeal nerve paralysis. J Voice 1994; 8: 79-83.

46 Stradling JR, Kozar LF, Dark J, et al. Effect of acute diaphragm paralysis on ventilation in awake and sleeping dogs. Am Rev Respir Dis 1987; 136: 633-637.

47 McCool FD, Tzelepis GE. Dysfunction of the diaphragm. N Engl J Med 2012; 366: 932-942.

48 Hart N, Nickol AH, Cramer D, et al. Effect of severe isolated unilateral and bilateral diaphragm weakness on exercise performance. Am J Respir Crit Care Med 2002; 165: 1265-1270.

49 Verin E, Marie JP, Similowski T. Cartography of human diaphragmatic innervation: preliminary data. Respir Physiol Neurobiol 2011; 176: 68-71.

50 Loukas M, Kinsella CR Jr, Louis RG Jr, et al. Surgical anatomy of the accessory phrenic nerve. Ann Thorac Surg 2006; 82: 1870-1875.

51 Markand ON, Kincaid JC, Pourmand RA, et al. Electrophysiologic evaluation of diaphragm by transcutaneous phrenic nerve stimulation. Neurology 1984; 34: 604-614.

52 Newsom-Davis J. Phrenic nerve conduction in man. J Neurol Neurosurg Psychiatry 1967; 30: 420-426.

53 Verin E, Marie JP, Tardif C, et al. Spontaneous recovery of diaphragmatic strength in unilateral diaphragmatic paralysis. Respir Med 2006; 100: 1944-1951.

54 McKinley WO. Late return of diaphragm function in a ventilator-dependent patient with a high cervical tetraplegia: case report, and interactive review. Spinal Cord 1996; 34: 626-629.

55 Oo T, Watt JW, Soni BM, et al. Delayed diaphragm recovery in 12 patients after high cervical spinal cord injury. A retrospective review of the diaphragm status of 107 patients ventilated after acute spinal cord injury. Spinal Cord 1999; 37: 117-122.

56 Perry SF, Similowski T, Klein W, et al. The evolutionary origin of the mammalian diaphragm. Respir Physiol Neurobiol 2010; 171: 1-16.

57 Bouvier J, Thoby-Brisson $\mathrm{M}$, Renier N, et al. Hindbrain interneurons and axon guidance signaling critical for breathing. Nat Neurosci 2010; 13: 1066-1074.

58 Koshiya N, Oku Y, Yokota S, et al. Anatomical and functional pathways of rhythmogenic inspiratory premotor information flow originating in the pre-Botzinger complex in the rat medulla. Neuroscience 2014; 268: 194-211.

59 Tan W, Pagliardini S, Yang P, et al. Projections of pre-Botzinger complex neurons in adult rats. J Comp Neurol 2010; 518: 1862-1878.

60 Thoby-Brisson M, Trinh JB, Champagnat J, et al. Emergence of the pre-Botzinger respiratory rhythm generator in the mouse embryo. J Neurosci 2005; 25: 4307-4318.

61 Wu J. Bases neurales de la respiration chez la souris: traçage monosynaptique et dissection génétique des neurones prémoteurs phréniques [Neural bases of breathing in the mouse: monosynaptic tracing and genetic dissection of phrenic premotor neurons]. Doctoral thesis, Paris, 2016. 